\title{
Waste Generated by Food Industry and Reuse in A Circular Economy Approach: The Whey Processing
}

\author{
F Rosa* \\ Professor at the University of Udine, Italy \\ Received: 钢 October 22, 2018; Published: 泚 October 26, 2018 \\ *Corresponding author: F Rosa, Professor at the University of Udine, Italy
}

\section{Mini Review}

The popularity of the circular economy is due to the increasing amount of waste-produced in the agro-food processing industry; new solution of waste recycling with biotech innovation are available. In the EU 3.5 ton per capita of waste are annually produced, including more than $400 \mathrm{~kg}$ per person per year of domestic waste. The projections suggest that this increase at worldwide level, will continue at least until 2030 and there is no real evidence of decoupling between waste and economic growth despite progresses in waste recycling. While all sectors are potentially eligible for funding under the Eco-innovation initiative, certain activities have been singled out as priority areas because of their considerable impact on the environment and their potential contribution to meeting the EU's own environmental objective. In the modern Agro-food system, the proper treatment of organic effluents to avoid their discharge as sewage water or sewage sludge, to prevent the pollution of the ground and water resources (oceans, lakes, rivers) is becoming especially important. Water is essential not only for direct uses, but also for ensuring the integrity of the ecosystems and the goods and services they provide to humans. The case we have considered is the whey, a by product of the cheese production, requiring urgent solutions to improve water efficiency and water quality used in the cycle.

\section{The Cheese Manufacturing and Whey Processing}

Cheese whey (CW) is the liquid part after milk has been curdled and strained in cheese production; it is the main by-product of the cheese making [1] After coagulation casein curd separates from the milk, under the action of chymosin or mineral/organic acid producing; the remain is the whey, a watery and thin liquid solution. Approximately from ten parts of milk, one part of cheese and nine parts of whey are produced with appreciable quantity of water soluble components [2]. It is estimated that the whey produced annually by the European dairy industry is about 75 million tons. it is a by-product of cheese making process, in the past it was discharged as waste into soil, rivers, lakes, causing pollution. When poured into a waterway, or sewer, the whey can deplete the water oxygen levels, causing serious environmental damage. The whey pollution is measured by the BOD and COD indexes (1.18) many authors have reported the following results: $\mathrm{BOD}_{5}$ varies between 30 and 60 thousand ppm $\left(35-45 \mathrm{~kg} / \mathrm{m}^{3}\right)$ while COD varies between 50 and 100 thousand ppm. $\left(50-100 \mathrm{Kg} / \mathrm{m}^{3}\right)$. According to Siso, only $50 \%$ of the total quantity of $\mathrm{CW}$ is treated and turned into non polluting products, then the whey wastewater disposal of the whey is becoming a major environmental problem in the world with the production of cheese whey is estimated over $10^{8}$ tonnes per year. The whey dispersion is now forbidden by recent legislation act. In Italy in 2015, 1.2 million tons of cheese and 9.5 million tons of whey were produced; in most of the northern regions the conversion ratio cheese/milk was around 1.1 to 10 due to the prevailing medium hard cheese while in the south the ratio around 1.4 to 10 for the prevailing production of mozzarella cheeses. The hard and semihard cheeses represent the 59\% of Italian production, followed by fresh and soft cheeses, with $41 \%$. Four Italian regions located in the northern regions: Lombardia, Emilia Romagna, Veneto and Piemonte produce almost seven million ton of whey representing the $72 \%$ of the total amount. Grana Padano is the most diffused hard cheeses accounting for $22 \%$ of total milk output. The first step of whey processing is the separation of the retentate fraction containing proteins from permeate fraction containing lactose; different methods are now available as ultrafiltration, diafiltration, inverse osmosis and nanofiltration. Our interest in Lactose is for its use in production of biopolymer namely PHA group after fermentations. PHA (polyhydroxy-alkanoate) is a collective name for a family of biodegradable intracellular bio-polymers made of chemically similar building blocks. PHB (poly-3-hydroxybutyrate) is the most widespread member of the PHA family produced by a wide range of prokaryotic genera starting from renewable feedstocks. A particular characteristic of PHA is its biocompatibility, making them suitable for medical applications. PHA also has good barrier properties, of interest for food product packaging. For these 
reasons, applications of PHA are found, for instance, in single-use packaging films, bags, containers, paper coatings, agricultural foils, biodegradable carriers for long-term dosage of compounds like drugs or fertilizers, and medical applications like surgical pins, sutures, wound dressings, bone and blood-vessel replacements. Currently, the industrial production of PHA by fermentation, is still a guess in terms of yield, extraction and economic sustainability as the production cost of plastics from petrochemical product is still more competitive and preferred by industrial companies compared to biopolymer production, however the two costs are converging rapidly. The environmental problems associated with the accumulation of traditional petrol derived plastics, due to the long-term degradation, makes urgent to find convenient bioplastic processing. The PHAs are polymers of carbon and reserve of energy accumulated in the cytoplasm of many bacterial species under particular conditions of excess of carbon availability, while some other factors are limiting (i.e. N, P, S, and other). These polymers can be synthesized in different types of PHA that microorganisms accumulate as insoluble inclusion in their bodies. The production of PHA from cost-effective substrates, such as agro-industry residues and specifically the whey is the interest of many researchers, interested in the dairy chain optimization and sustainability. The whey is a by-product of the cheese production chain; in volume represents the $80-90 \%$ of the milk converted into cheese. Sweet skimmed whey is subjected to a concentration step, removing $80 \%$ of its water content. A convenient solution is to extract proteins from retentate fraction and sell into separate market outlets. The permeate fraction rich in lactose (45gr/liter) is a carbon source for different metabolic pathways. We concentrate in the lactose fermentation to produce PHA; a number of studies identified many microbial groups able to synthesize these polymers, the most important are the Rastonia group, the Escherichia coli, the Capriovidus Necator. These bacterial species are the most used for industrial application since they associate high productivity and reduced times of PHA accumulation. The PHA accumulation speed is very variable: specific rate $0.15 \mathrm{~g} / \mathrm{g} * \mathrm{~h}$ equivalent to $15 \%$ yield per hour; $16.8 \mathrm{~g} / \mathrm{L}$ biomass containing 73\% PHA were obtained Koller [3].

\section{Biodegradability}

Majority of the strains that are able to degrade PHA belong to different taxa such as Gram-positive and Gram-negative bacteria, Streptomyces and fungi. It has been reported that 39 bacterial strains of the classes Firmicutes and Proteobacteria can degrade PHA, PCL, and PBS, but not PLA. The population of aliphatic polymerdegrading microorganisms in different ecosystems was found to be in the following order: PHA > PCL > PBS > PLA. Microorganisms secrete enzymes that break down the polymer (PHA depolymerize) into its molecular building blocks, called hydroxyacids, which are utilized as a carbon source for growth. While degradation by mesophilic temperatures, microorganisms which are capable of degrading various kinds of polyesters at high temperatures are of interest. A thermos-tolerant Aspergillus sp. was able to degrade $90 \%$ of PHA film after five days cultivation at $50{ }^{\circ} \mathrm{C}$. In the $1980 \mathrm{~s}$, Imperial Chemical Industries developed poly (3-hydroxybutyrateco3-hydroxyvalerate) obtained via fermentation that was named 'Biopol'. It was sold under the name 'Biopol' and distributed in the U.S. by Monsanto and later Metabolix.

Researchers in industry processing are working on methods with which transgenic crops will be developed that express PHA synthesis routes from bacteria to produce PHA as energy storage in their tissue. Commercial ventures scaling up PHA production using fermentation processes include Telles, USA; Biomer Biotechnology Co., Germany; PHA Industrial, Brazil; Mitsubishi Gas Chemical, Japan; Kaneka, Japan; Biomatera, Italy; Jiangsu Nantian Group, China; Tianan Biologic Material, China; and Lianyi Biotech, China. PHAs is a very versatile precursor of bio-plastic materials that raise the attention of different industrial branches. As the best-known and most simple application, these biopolymers are of interest for packaging purposes, especially in such areas where compostable packaging is wanted, e.g. in the food producing industry. Especially in the field of packaging of easily spoiling food, the high oxygen barrier of PHA films is very beneficial. In addition, bottles for shampoos (Wella, Germany) made of PHAs were commercially available in the past. PHAs can be used for paper coating, production of daily commodity items like razors, diapers, hygiene products, or cups and dishes (Metabolix, USA; BASF, Germany). For these applications, PHAs can be processed by techniques of injection moulding or film blowing using the same equipment as known from the well-established processing of petrochemical plastics. In the medical field, PHAs were already investigated as bone implant materials, for tissue engineering, for in-vivo application as implants, surgical pins, screws, meshes and sutures, and as carrier matrices for controlled drug release. Also the production of highly sophisticated surgical articles such as artificial blood vessels and vein valves, spinal fusion cages, bone marrow scaffolds, and meniscus regeneration devices. Especially the possibility to change the composition of PHA allows the manufacture of materials with tailor-made mechanical properties and a fine-tuned degradation rate under in-vivo conditions.

\section{Economic Caveat}

Three main problems have to be afforded to make the bioplastic production feasible:
i. cost of feedstock
ii. cost of downstream process
iii. Industrial cost and optimal scale. The feedstock costs are limited by the need to recycle a great amount of whey in intensive cheese production. 
By the way marketing opportunities for whey proteins and lactose are growing and compete with PHA production. The $2^{\text {nd }}$ problem is the optimization of the downstream processing for PHA recovery and refining after cell harvest. As intracellular products, PHAs have to be separated from the surrounding non-PHA cell mass, mainly consisting of proteins, lipids, nucleic acids and special polysaccharides. Here, high input with often highly polluting solvents and enormous energy demand still are the caveat in PHA recovery, compromising the demanding claims of these bio-plastics to be ecologically sound materials. The $3^{\text {rd }}$ problem implies to afford the increasing productivity by designing the optimal engineering plant for the final break-through of these biopolymers on the market. A continuous biotechnological production process is well known as an interesting solution for achieving high productivity, lower costs and constant product quality. Some authors reported high productivities of $1.85 \mathrm{~g} / \mathrm{L} \mathrm{h}$ for $\mathrm{PHB}$ and a constant and satisfying product quality using Cupriavidus necator strain.

To optimize the entire PHA chain, we suggest the following steps:

a) Optimize the collection whey costs from a basin area of enough size to cover the costs and minimize the environmental cost of transport [4].

b) stabilize the whey quality and improve the efficiency of the whey processing through advanced membrane methods of ultrafiltration, nanofiltration, inverse osmosis. c) Find new bacterial strain to convert directly and more efficiently the lactose into PHA, avoiding the feast-famine two step fermentation.

d) optimize the scale of the chain. Some industries achieved the break point of biopolymer cost production with traditional plastic derived from petroleum (around $1.5 / \mathrm{Kg}$ ) with scale production of 40 thousand ton per year [5-7].

\section{References}

1. Orhon D, Görgün E, Germirli F, Artan N (1993) Biological treatability of dairy wastewaters. Water Res 27(4): 625-633.

2. Jelen P (2003) Whey processing: Utilization and products. In: Roginski H, Fuquay JW, Fox PF, (Eds.). Encyclopedia of Dairy Sciences. New York, USA: Academic pp. 2739-2745.

3. Koller M, Gasser I, Schmid F, Berg G (2011) Linking ecology with economy: insights into polyhydroxyalkanoate-producing microorganisms. Engineering in life sciences 11(3): 222-237.

4. Iseppi L, Rosa F, Taverna M (2017) Optimize the Transport Cost and Environmental Impact of Whey Collection: A Case Study in the Region Trentino A. A. (Italy). American Journal of Operations Research 7(3): 153-173.

5. Audic JL, Chaufer B, Daufin G (2003) Non-food applications of milk components and dairy co-products: a review. Lait 83(6): 417-438.

6. Siso (1996) The biotechnological utilization of cheese whey: A review. Bioresour Technol 57(1): 1-11.

7. Koller M, Hesse PJ, Bona R, Kutschera C, Atlic A, et al. (2007) Biosynthesis of High Quality Polyhydroxyalkanoate Co- and Terpolyesters for Potential Medical Application by the Archaeon Haloferax mediterranei. Macromolecular symposia 253(1): 33-39.

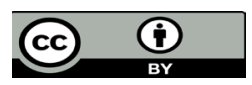

This work is licensed under Creative Commons Attribution 4.0 License

Submission Link: Submit Article

DOI: $10.32474 /$ CDVS.2018.02.000132

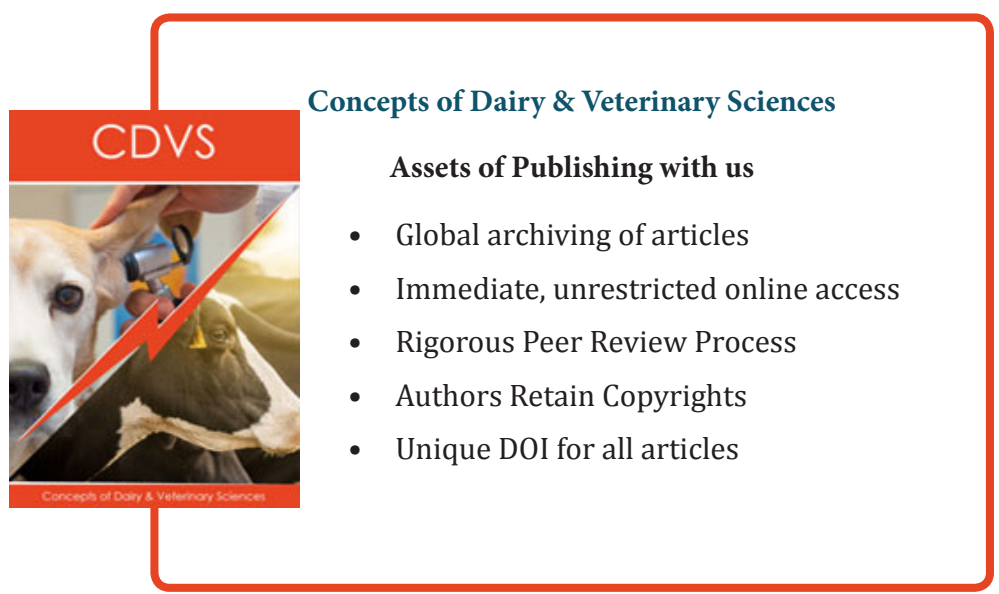

